\title{
Gender differences in working at home and time use patterns: Evidence from Australia
}

\section{Abigail Powell and Lyn Craig}

\begin{abstract}
Despite a wealth of research on working at home (WAH), few studies have examined the effects of WAH in relation to its regularity, and fewer still have used time use studies to do so. Using data from the 2006 Australian Time Use Survey this article investigates the association between WAH, gender and time use patterns, in relation to amount of time spent in paid work, unpaid work and recreational labour, as well as multi-tasking, fragmentation of time and scheduling flexibility. It examines time use patterns according to whether employees do no WAH or whether they WAH rarely, occasionally or regularly. Results show there is an association between WAH and time in paid and unpaid work, and this association differs by the regularity of WAH and gender. WAH does not create more time for recreational labour, although it does appear to help women juggle work and family.
\end{abstract}

Keywords: employees, gender, time use, work at home, work-life balance

\section{Introduction}

In recent years there has been renewed interest in the concept of working at home (also referred to as homework and telework), with its potential to offer workplace flexibility hotly debated among industry, media, policy-makers and academics. Working at home is argued to offer a range of benefits, including making it easier to juggle work and non-work activities, such as family responsibilities or leisure time (e.g. Baines and Gelder, 2003), since it can provide greater control and flexibility around the pace and timing of work. As such, working at home is now available to many employees as part of a wider suite of flexible working options (e.g. Boulin et al., 2006); in Australia, 24\% of the workforce work at least some hours at home (ABS, 2009). However, working at home is prevalent among a diverse range of people and it is unlikely that it offers equal potential for flexibility across groups where it is prevalent, including: low skilled workers on low wages; high skilled workers with high levels of agency; and self-employed people (Ammons and Markham, 2004; Bailey and Kurland, 2002; Felstead et al., 2001; Nätti et al., 2011). Research also shows that time spent on unpaid work and in leisure, and indeed working at home, are gendered. This paper therefore examines the relationship between working at home and time use patterns by gender.

Although a substantial literature on the nature and effects of working at home exists, most are either small qualitative studies focusing on those who work exclusively from home, or quantitative studies comparing effects and outcomes of working at home versus site-based work in specific industries, occupations and organisations. A limited number of studies use nationally representative datasets but few have utilised the wealth of data available from time use studies (for an exception see Nätti et al., 2011). This is a significant gap, addressed in this article, since time use studies offer the opportunity to examine the relationship between working at home and time use patterns in a number of ways. Time use studies are self-reported diaries that detail how individuals spend their time over a given number of days, recording what activities they do, when, where, how long for, who with, and whether they were doing 
anything else at the same time (multi-tasking). Such studies are also particularly useful for identifying gender differences in time use patterns.

The working at home literature predominantly focuses on paid (employment) and unpaid work (domestic labour and childcare), with little consideration of other aspects of 'life'. Ransome (2007) suggests we also examine 'recreational labour', which includes sleep, leisure, self-care and socialising. Ransome argues that paid and unpaid work are both necessary labour, whereas recreational labour, 'is performed through practices of leisure, pleasure and enjoyment', is more open and subjective and more likely 'freely chosen' (2007: 378). Of particular significance for this article is the notion that employees need leisure time to detach from work (Sonnentag, 2001) and that leisure time may be gendered in both amount and quality (Sullivan, 1997) (Author 2013).

This article addresses these issues by examining i) whether the amount of time spent in paid work, unpaid work (domestic work and childcare) and recreational labour (personal care, leisure and sleep) differs by working at home arrangements; and, ii) the extent to which working at home is associated with flexible time use patterns, including multi-tasking, fragmentation and scheduling of paid work time. Amount and flexibility in time use are important features of how individuals' experience time. They are particularly interesting against a background that on the one hand suggests working at home may better enable employees to integrate their work and home lives, and on the other indicates that the blurring of boundaries that can occur when people work at home may be a source of stress and a challenge to managing work and non-work activities. To examine nuances in time use patterns, we compare four working at home (WAH) arrangements by diary day: i) no WAH; ii) WAH rarely - worked at home, but do not usually; iii) WAH occasionally - worked at home and usually do so for less than 50 per cent of employment hours; and iv) WAH regularly - worked at home and do so for $50 \%$ or more of employment hours. Because much of the literature points to the gendered take-up and effects of WAH, the article also examines whether this differs by gender.

\section{Effects of working at home on time use patterns}

As noted above, WAH is argued to offer a range of benefits, most notably making it easier to juggle work and life (Baines and Gelder, 2003; Sullivan and Lewis, 2001; Redman et al., 2009; Hill et al., 2003). This is largely because it is seen to provide greater control and flexibility in relation to the pace and timing of work. WAH is believed to enable scheduling flexibility (Kurland and Bailey, 1999; Mann and Holdsworth, 2003), for example scheduling work hours around children's school times (Demerouti et al., 2014). It is also understood to reduce timebased work-family conflict (Ammons and Markham, 2004); create time savings, for example less time commuting (Hill et al., 2003), not getting dressed, finding ways to perform work and home tasks simultaneously, such as taking care of children while working (Ammons and Markham, 2004); and minimise workplace interruptions, particularly if it is an occasional arrangement (Bailey and Kurland, 2002). WAH is also thought to have a positive effect on job satisfaction and work autonomy (Kurland and Bailey, 1999; Redman et al., 2009). Maruyama et al (2009), in a single organisation study, concluded that WAH provided greater autonomy over when to work and that the ability to use hours flexibly was the most important factor in balancing work and life demands. This may explain Baruch's (2000) finding that WAH may be an alternative to opting out of the workforce when traditional working arrangements cannot 
accommodate both work and family demands. Arguably, however, many workers require workplace autonomy in order to WAH (e.g. Felstead et al., 2001).

The positive effects of WAH are contested (Sullivan and Smithson, 2007; Morganson et al., 2010), with a number of negative implications highlighted such as professional and social isolation and diminished career progression (Kurland and Bailey, 1999; Mann and Holdsworth, 2003). Many who WAH are also thought to work long or extended hours (Golden, 2008; Nätti et al., 2011). Peters and Van der Lippe (2007) suggest that longer working hours among those who WAH may be attributable to the lack of 'checks and balances' such as workload comparison with co-workers.

Significantly, both spatial and temporal boundaries between work and home are likely blurred for those who WAH, which may be challenging for some workers (Ammons and Markham, 2004; Berke, 2003; Mann and Holdsworth, 2003; Sullivan and Lewis, 2001). Increased boundary work may be particularly detrimental to managing work and non-work activities. For example, employees working at home are more likely to mix paid employment with domestic work and childcare during conventional hours, to have their work time interrupted by other tasks and responsibilities, and extend their working hours into the evening (Hill et al., 2003). Such mixing of tasks may be referred to as multi-tasking (doing two or more activities simultaneously) or time fragmentation (switching repeatedly between tasks or having one activity continuously interrupted by another) and may either be a result or consequence of time pressure. While doing two things at once seemingly allows people to get more done in a limited amount of time (Offer and Schneider, 2010), Rubinstein et al. (2001) found that there are time costs involved in switching between tasks. Performing work and family roles in the same place may therefore increase, rather than reduce, stress, especially when non-work demands for attention coincide with job deadlines (Ammons and Markham, 2004). Bittman and Wajcman (2000) argue that both multi-tasking and fragmentation of time impact negatively on the quality of how time is experienced. They and others (Sullivan and Gershuny, 2013; Bianchi and Milkie, 2010; Sayer, 2007) have also found multi-tasking and/or time fragmentation to be highly gendered. Therefore this paper examines both multi-tasking and fragmentation of employment, concepts described further in the method.

As Sullivan and Smithson (2007) note, perhaps the most important conclusion is that scheduling flexibility and the blurring of home-work boundaries should not be regarded as intrinsically positive, not least because the meaning of work-life balance varies from person to person (Maruyama et al., 2009). In other words, for some people the interaction and blurring of work and home is inappropriate and therefore stressful when it occurs, whereas for others integrating work and home may be more legitimate and therefore support them to manage work and non-work. To some extent, this experience depends on a range of personal, household and work characteristics and circumstances (Felstead and Jewson, 2000; Demerouti et al., 2014), a number of which we discuss below.

\section{Gender}

The literature suggests gender is one of the most significant variables affecting the experience of WAH (Sullivan and Lewis, 2001). Although WAH was been heralded as enabling a breakdown of traditional genders roles, via the lack of separation between work and family (Silver, 1993) this has not materialised. In fact, in many cases WAH has reinforced the domestic burden of women and perpetuated the marginalization of female employment (Sullivan and Lewis, 2001). Sullivan and Smithson (2007), for example found that WAH 
supported gender equity in households that were already egalitarian and made minimal difference in more traditional households. Research on other flexible work arrangements echoes this sentiment (Gambles et al., 2006) (Author 2011).

Ammons and Markham (2004) suggest women may find it particularly hard to maintain boundaries given gendered demands and expectations around domestic work and care. Such responsibilities make it difficult to avoid interruptions to and fragmentation of employment activities (see also Mann and Holdsworth, 2003). From their qualitative study, Sullivan and Smithson (2007) concluded that flexibility was seen as beneficial to women working at home because it facilitated their domestic work and mothering role. Employment may even be combined simultaneously with domestic work and care. Working at home while supervising children, for example, may enable employed parents to have greater presence in their children's lives (Callister and Singley, 2004). For men, the flexibility of WAH is more likely to be seen as a means of controlling their paid work, although it may enable them to 'help' more with domestic work and childcare and spend more time with their family (Sullivan and Smithson, 2007). In other words, women may be more likely to WAH to accommodate work and family demands, while men may be more likely to WAH to facilitate additional employment time. These findings are echoed elsewhere with research indicating WAH is a less common strategy for juggling work and non-work among men than women, particularly those with children (Berke, 2003; Hilbrecht et al., 2008). Sullivan and Smithson (2007) conclude, however, that differences among people who WAH are less about gender, and more about dependent children. Also, on a positive note, Felstead and Jewson (2000) argue that given the gendered nature of domestic work, WAH may provide women with an opportunity to exercise power and control.

\section{Differences in working at home arrangements}

Another key indicator of the experience of WAH is the proportion of working time spent at home (Sullivan, 2003). Evidence suggests that people who typically WAH do so infrequently, for example a few days a month or to supplement site- or office-based work (Bailey and Kurland, 2002; Haddon and Brynin, 2005). Despite this, research has focused primarily on people who WAH regularly or full-time, leaving a significant gap, as noted by Morganson et al (2010). This article addresses this gap, as the few studies that have examined this issue have found substantial differences between those who WAH regularly and those who WAH occasionally. For example, Felstead et al (2001) found that among those working mainly at home, women outnumber men, while the opposite was true among those who WAH less regularly. Peters and Van der Lippe's (2007) Dutch study examined WAH's potential for reducing time-pressure. They categorised workers according to the frequency of WAH since this may influence the effects: 1) onsite workers; 2) occasional (less than one day per week; 3 ) light (one day per week); 4) heavy (more than one day per week). The study examined a range of indicators that may be indicative of time pressure, but their survey did not include time use data. Golden and Veiga (2005) found that the relationship between WAH and job satisfaction was curvilinear; those with moderate levels of WAH reported the highest levels of satisfaction.

\section{Other work characteristics}

As noted above, evidence indicates that people who WAH work long hours. Felstead and Jewson (2000), for example, found that WAH was more prevalent among long hours workers, since they tended to supplement their office hours. However, Kelly et al (2008) found part- 
time workers rather than full-timers were more likely to WAH. This may partially explain gender differences in WAH, since women are more likely than men to work part-time. In their qualitative Swedish study, Michelson and Linden (1997) found that gender was less important for boundary management than hours of work (full-time/part-time) and length of time spent in the home. There are mixed findings in the limited research on the relationship between WAH and sector. While the public sector is often thought to promote flexible working arrangements to a greater extent than the private sector, Felstead et al (2002) found that WAH was most prevalent among employees in the public sector and those in the unionised private sector.

Working at home is most common in managerial and professional occupations and in knowledge-intensive industries (van den Broek and Keating, 2011), where there are high levels of autonomy about when and where to work (Ammons and Markham, 2004; Felstead et al., 2001; Nätti et al., 2011). Given that these occupations and industries are often male-dominated, this is also likely to impact on the gendered effects of WAH. WAH is also prevalent among low skilled workers on low wages undertaking repetitive tasks (Felstead et al., 2001; Nätti et al., 2011). Not only does the ability to WAH apply to certain occupational groups, it also likely impacts on them differently. Callister and Dixon (2001) found that the homes of people in the higher-skilled occupations are more suited to WAH, with more space and sometimes separate rooms for offices. Nevertheless, many studies of WAH have focused on specific sub-groups of occupations or industries, and therefore fail to address whether the experiences they identify are typical of all people who WAH (e.g. Redman et al., 2009; Ammons and Markham, 2004; Berke, 2003; Halford, 2006; Mann and Holdsworth, 2003). Given that WAH is most prevalent among managers and professionals, it is not surprising that highly educated groups are more likely to WAH than less qualified groups (Callister and Dixon, 2001). Other research suggests that while overall prevalence may not be greater among more highly educated workers, they may have particular patterns of WAH, such that Peter and Van der Lippe (2007) found they were less likely than others to WAH regularly (less than one day per week on average). Evidence also suggests that high levels of education and professional occupations are positively associated with multi-tasking (Schieman and Young, forthcoming).

The aim of this research is to further the debate on WAH by using time use data to examine the relationship between WAH and time use patterns. Specifically it asks: 1) how does WAH relate to the quantity and quality of time spent on paid work (employment), unpaid work (domestic work and childcare) and (following Ransome, 2007) 'recreational labour' (sleep, personal care and leisure)? Given the gendered nature of employment, unpaid work and leisure, it also asks: 2) how does this differ by WAH arrangement and gender? Note that we focus on the relationship between WAH and time and do not identify cause and effect.

\section{Research method}

Data are from the most recent Australian Bureau of Statistics 2006 Time Use Survey (TUS), which contains a nationally representative sample of Australian households. All aged 15 years and over in sampled households are required to provide information. Respondents record their main (primary) activities, any simultaneous (secondary) activity, who they are with and where they are throughout the day, to a detail level of five-minute intervals over two days. The survey collects demographic information on respondents and their households and additional survey data, including the number of hours a week employees usually WAH.

The sample is restricted to diaries of employees of working age (15-64 years) who recorded employment time on the diary day. Self-employed are excluded from the analysis since we 
expect their employment patterns to be substantively different to employees (Author, 2012). Respondents with more than two hours of activity information missing from their time diaries are excluded. This yields a sample of 2589 respondents who completed the time use diary on one or two days, resulting in a total 4143 completed diary days (a number of respondents recorded employment time on only one day). Analyses account for clustering of persons within households and diaries within persons. Analytic weights supplied with the data are also applied to ensure an equal distribution of days of the week. A full sample description is provided in the technical appendix: Table A1.

The independent variable is working at home arrangement. This variable is derived by first establishing whether people worked at home on the diary day, using the physical location they reported in their diary; and second, examining responses to the survey question "how many hours per week [do you] usually work at home?" These responses are categorised into four arrangements: 1) did not WAH on the diary day; 2) WAH rarely - worked at home on the diary, but do not usually work at home; 3) WAH occasionally - worked at home on diary day and usually work at home for less than 50 per cent of employment hours (WAH<50\%); and 4) $W A H$ regularly - worked at home on diary day and usually work at home for $50 \%$ or more of employment hours (WAH=>50\%).

The dependent variables examine both time quantity (amount) and quality (multi-tasking, time fragmentation and scheduling):

1. Amount of time spent in a) employment, disaggregated into employment and employmentrelated travel; b) unpaid work, disaggregated into domestic work (includes housework, meal preparation, laundry, household management and maintenance) and childcare (includes talk-based care, physical care and supervision); and c) recreational labour, disaggregated into sleep, personal care (personal hygiene, health care, eating and drinking) and leisure (visiting entertainment and cultural venues, religious activities, sport, games, craft, reading, watching TV, listening to music). Each of these is measured as mean daily minutes spent in each activity per diary day.

2. Multi-tasking. Multi-tasking is defined as doing multiple tasks at the same time. It is identified in time diaries when two activities (main activity and secondary activity) are reported for the same time period. Multi-tasking in time use studies can be problematic since some respondents may only record their primary activity, even if they were doing another activity simultaneously. This is particularly thought to be the case in relation to multi-tasking employment and other activities (Sullivan and Gershuny, 2013). However, recording of secondary activities is relatively high in our sample: $91 \%$ of diary days recorded some secondary activities $(\mathrm{n}=3759)$ and $61 \%$ record a primary employmentrelated activity and a secondary activity $(\mathrm{n}=2511)$, with an average 116 mins of secondary activity reported. We focus explicitly on time spent in employment-related activities while simultaneously recording childcare activity ( $\mathrm{n}=138$ diary days). Other multi-tasking with employment is excluded, as it mostly comprises multi-tasking with leisure activities, such as listening to the radio. Multi-tasking of employment and domestic work is also excluded as very little of this is undertaken (only 51 diaries report it). Multi-tasking is reported in minutes per day.

3. Time fragmentation. Because multi-tasking data is limited and very few tasks can genuinely be carried out simultaneously, we also analyse time fragmentation, by counting respondents' activity episodes. Each time a respondent starts a new activity in their time 
diary this is classified as a new activity episode, enabling a count of total number of episodes during a day. This is important because employees may spend the same total amount of time in employment activities, but this can be experienced either as one continuous activity (i.e. a solid block of time) or as time interspersed, or interrupted, by other activities, which may speak to the quality of people's time (Mattingly and Bianchi, 2003; Bittman and Wajcman, 2000) and the intensification of work (Callister and Singley, 2004).

4. Time scheduling. Tempograms show daily scheduling of employment activities to determine whether paid work is organised differently according to WAH arrangements. We calculate the mean number of minutes spent in employment at each hour of the day.

\section{Analysis plan}

We present descriptive analyses of the dependent variables by WAH arrangements and gender. We also present multivariate regression analyses on amount of time in the dependent variables, multi-tasking and fragmentation of time. We run separate models by gender, because men and women experience time differently, particularly in terms of paid and unpaid work, and also because the nature of WAH may be gendered, as discussed above. This is supported by our own preliminary analysis of the data, which directly tested gender differences (see Table A3). The first models are OLS regressions on the amount of time spent in employment, domestic work, childcare, personal care, sleep and leisure, as well as multi-tasking. Poisson (count) models test whether working at home is associated with the number of episodes employees spend in paid work on the diary day. For ease of interpretation we present marginal effects in the Poisson models rather than coefficients.

The independent variable of interest is WAH arrangement, as described above; no WAH on the diary day is omitted. The models control for other variables that may be independently associated with time use and WAH. These are: occupation (non-professional omitted/professional=1) and education (no degree omitted/tertiary degree $=1$ ), since both of these have been identified as contributing to job autonomy and capacity to WAH (e.g. Ammons and Markham, 2004; Felstead et al., 2001; Nätti et al., 2011), but also job demands such as long work hours; sector (private omitted/public=1), as evidence has shown differences in WAH arrangements by sector (e.g. Felstead et al., 2002); relationship status (has spouse (married or defacto) omitted/no spouse $=1$ ), as previous research indicates that although those who are married are more likely to WAH (Golden, 2008), it is only effective in enhancing work-life balance for singles (ten Brummelhuis and Van Der Lippe, 2010); whether respondent has children aged under 15 years (yes omitted $/ \mathrm{no}^{=1}$ ), as the presence of children has been found to impact particularly on women's decisions to WAH and also has a clear relationship with amount of time spent on childcare (e.g. Author, 2011). We also control for whether the diary day is a weekday (omitted) or weekend. The Poisson model examining employment episodes also controls for usual hours of work (part-time/full-time (omitted)/long hours (over 50 per week), since the total hours spent in employment has a clear relationship with the number of episodes worked. Due to space constraint and because effects are in line with expectations, we do not discuss the control variables; full models are detailed in the technical appendix.

\section{Results}

The majority of the sample did no WAH on the diary day $(72.8 \%) ; 12.2 \%$ did WAH on the diary day, but reported that they did not usually WAH (WAH rarely); $11.8 \%$ worked at home 
on the diary day but WAH occasionally (for less than $50 \%$ of their total employment hours); and only 3.2\% worked at home on the diary day and reported WAH regularly (for $50 \%$ or more of their total employment hours). Men were more likely than women to do no WAH on the diary day (76.2\% compared to $68.6 \%$ ), while women were more likely to WAH rarely $(14.5 \%$ compared to $10.3 \%)$ and to WAH regularly $(5.1 \%$ compared $1.7 \%)$. For further information on how sample characteristics differed by working at home status see the technical appendix (Table A2).

\section{Amount of time}

Table 1 panel A presents the mean number of minutes per day men and women spend in major time activities by their WAH arrangement. On average men spend much longer than women on employment, regardless of WAH arrangement. For both men and women, employment time (excluding travel) is highest for those who do no WAH (men 481mpd; women 409mpd), followed by those who WAH rarely (men $442 \mathrm{mpd}$; women $345 \mathrm{mpd}$ ), those who WAH occasionally (men $411 \mathrm{mpd}$; women $339 \mathrm{mpd}$ ) and those who WAH regularly (men 446mpd; women $238 \mathrm{mpd}$ ). For women, amount of time in employment is substantially lower for those who WAH regularly, while for men, the lowest work hours are among those who WAH occasionally. The difference in time spent in employment across working arrangements is much more varied for women than men. As would be expected, employment-related travel, or commuting, is highest among both men and women who do not WAH and lowest among those who WAH regularly.

Women spend more time than men on domestic work and childcare overall and their time in these activities is more varied according to their WAH arrangements than for men. Women who WAH regularly spend much longer on domestic work and childcare compared to other women, with time spent on these activities increasing with the regularity of WAH. Men who WAH on the diary day do more domestic work than those who did not, with little variation by WAH status. However, men who WAH occasionally have the highest childcare time.

For both men and women there is little variation in time spent on personal care, sleep or leisure time. Nevertheless, personal care time is highest among men who WAH occasionally and lowest among men who WAH rarely, whereas for women it is highest among those who do not WAH and lowest among those who WAH regularly. For both men and women, sleep is highest among workers who WAH rarely. However, sleep time is lowest among women who do no WAH and among men who WAH regularly. Leisure time is lowest for both men and women who do no WAH on the diary day. For men, leisure time is highest among those who WAH regularly, while for women it is highest if they WAH rarely. The biggest difference between men and women's leisure times (42mpd) is among those WAH regularly.

\section{[TABLE 1 here]}

Table 2 summarises the multivariate models (full models are available in the technical appendix). Each row summarises a different model and each column reports the main effects on the independent variable: WAH. Panel A presents the OLS analyses of the amount of time men and women spend in employment, domestic work and childcare. Examining men, both those who WAH rarely and occasionally $(<50 \%)$ spend significantly less time in employment and employment-related travel and significantly more time on domestic labour and sleep than men who did no WAH on the diary day. Men who WAH rarely spend significantly less time on personal care (which may indicate less time spent getting ready for work); while those who 
WAH at home occasionally spend significantly longer on childcare. Most of these differences are substantively small, $10-20 \mathrm{mpd}$, with the exceptions of employment, which were $30 \mathrm{mins}$ (WAH rarely) and 42 mins (WAH $<50 \%$ ).

By contrast, women's time spent on employment, employment related travel and domestic labour differs significantly across all WAH categories. Differences in paid work and domestic work are substantial. Women who WAH rarely or occasionally spend approximately one hour less on employment than women who do not WAH, while women who WAH regularly spend 2.5 hours less on employment. Women's time in domestic work also increases substantially with the regularity of time spent WAH. Compared to those who do no WAH, women who WAH occasionally spend $12 \mathrm{mpd}$ longer doing childcare, and women who WAH regularly spend 78mpd longer doing childcare. Personal care, sleep and leisure have fewer differences, with only sleep and leisure time being significantly longer among women who WAH rarely compared to women who do no WAH.

\section{[TABLE 2 here]}

\section{Multi-tasking}

Table 1, Panel B shows that across most WAH arrangements, women spend more time multitasking employment and childcare than men. The exception is that men average marginally higher multi-tasking than women among the occasional WAH group (6.0mpd, compared to $4.9 \mathrm{mpd})$. For men and women, multi-tasking employment and childcare is highest when they WAH regularly, albeit four times longer for women $(24.2 \mathrm{mpd})$ than men $(6.3 \mathrm{mpd})$.

Table 2, Panel B summarise the OLS models of employment time (minutes per day) multitasked with childcare. It shows that on average multi-tasking is substantively low for both men and women. Working at home arrangements have different associations with multi-tasking for men and women, with women averaging higher levels of multi-tasking than men. For men, significantly more time is spent multi-tasking if they WAH occasionally compared to those who do no WAH. Among women, compared to those who do not WAH, women who WAH regularly average significantly more time multi-tasking ( $21 \mathrm{mpd}$ respectively).

\section{Time fragmentation}

To indicate fragmented or interrupted time, we examine average daily number of employment episodes (Table 1, Panel C). For men, employment episodes are fewest for those who do not WAH (2.7) and increase the more regularly they WAH. In contrast, for women, while employment episodes are also fewest when they do no WAH (2.7), they are highest when they WAH occasionally (4.0). This suggests WAH is either scheduled flexibly around, or interrupted by, non-employment activities. Table 2, Panel $\mathrm{C}$ summarises the Poisson model results. It confirms that employment is more fragmented when people WAH and increases significantly with the regularity of WAH. Men's time in employment appears more fragmented than women's if they WAH occasionally or regularly, although this is not tested statistically.

\section{Time scheduling}

Figure 1 demonstrates how employees schedule their employment according to their WAH arrangements. It illustrates earlier findings that men spend more time on employment activities than women, but that this is particularly the case among those employees who WAH on the 
diary day. For both men and women who do not WAH, employment time is concentrated around traditional work hours (between 9am and 5pm). However, employees who WAH spend less time working 'traditional hours' and more time working in the evening/night, although this difference is substantively small. This is particularly the case for men who WAH regularly, who spend more time working between $5 \mathrm{pm}-11 \mathrm{pm}$. It is also slightly more evident among women who WAH rarely, who spend more time working between 6-8pm and slightly more time between midnight and 7am. This illustrates that employees who WAH schedule their paid work differently to those who do not.

\section{[FIGURE 1 here]}

\section{Discussion and conclusion}

This article set out to identify what happens when employees work at home in terms of the amount of time they spend in paid and unpaid work and recreational labour, as well as the extent to which paid work is associated with flexibility and blurred boundaries, measured by examining multi-tasking, fragmentation and scheduling. Importantly, it examined each of these outcomes by gender and distinguished between employees who did no WAH on the diary day, and those who worked at home on diary day with different patterns of regularity.

Different WAH arrangements were associated with different patterns of time use in employment, domestic work and childcare (more so for women than for men), but had few associations with time spent on 'recreational labour' (sleep, personal care and leisure: Ransome, 2007) for either gender. More broadly, this shows that variation in time patterns by working at home arrangements is largely a result of shifting time between paid and unpaid work (domestic labour and childcare), not between paid work and recreational labour. Arguably this indicates that WAH does not enable workers to have better work-life balance, as it implies they are most likely to spend the time they gain on a different kind of work, rather than leisure pursuits or 'life' outside work.

The analyses indicated that the average employee, male or female, spent significantly less time on employment activities if they worked at home compared to if they did not. Also illustrated by the tempograms, this disputes existing research suggesting people who WAH work long hours (e.g. Ammons and Markham, 2004; Golden, 2008; Nätti et al., 2011). The tempograms do however illustrate that people who WAH schedule less employment in 'traditional hours' and more in the evening, which may make it more difficult for individuals to make an assessment of their total working time and compare themselves with their co-workers (Peters and Van der Lippe, 2007). For men, the reduced time in paid work was most notable if they WAH rarely or occasionally. Only men who WAH occasionally spent more time on childcare activities, disputing arguments that men will do more domestic work if they are at home more (Silver, 1993).

It also contrasts with women's experiences of working at home. There was more variation in women's time in employment and unpaid labour by WAH arrangements compared with men. The differential impact by gender is particularly notable among those who WAH regularly. While men's time did not vary significantly between those who WAH regularly and not at all, women's time was significantly and substantively different. Women who WAH regularly (compared to those who did no WAH) spent significantly less time on employment activities and significantly more time on domestic work and childcare. The finding that women, more than men, change their time and routine is supported by other research and is consistent with 
norms that women, not men, shoulder the responsibility for managing family time (Author, 2011) (Pocock et al., 2012). Although the analysis is not causal, it suggests working at home regularly reinforces the domestic burden of women (Sullivan and Lewis, 2001), and therefore gender inequity around paid and unpaid work. It suggests women are more likely than men to WAH to accommodate work and family demands (Sullivan and Smithson, 2007) and that for women WAH may be an alternative to opting out of the workforce completely (Baruch, 2000). More broadly, it confirms that men's paid work time is much less contingent on other factors than women's (Mattingly and Sayer, 2006) (Author 2011). This conclusion is underlined by the data on multi-tasking and scheduling of paid work.

Fragmented time and multi-tasking are largely viewed negatively in the literature. This is due to 'difficulties' maintaining boundaries and 'avoiding interruptions' (Ammons and Markham, 2004; Mann and Holdsworth, 2003) and since it signals time pressure as people squeeze more tasks into limited time (Offer and Schneider, 2010). However, the finding that women do more childcare and more multi-tasking if they WAH regularly suggests these women have chosen to WAH precisely for this purpose. Sullivan and Lewis (2001) similarly found that some of the teleworkers they interviewed combined tasks as a deliberate strategy and this was viewed as an advantages of WAH; WAH reportedly helped with carrying out domestic work. Evidence also points to combining tasks being more common among women than men (Sullivan and Lewis, 2001). Halford (2006), on the other hand, suggests that researchers give up yearning for boundaries, arguing that there is diminished need for them. Again this argument is supported by the tempograms, which show that scheduling of paid work is different for those who WAH and those who do not. Nevertheless it can be argued that the 'choice' to combine tasks and minimise boundaries between work and family is one constrained by structural issues, that make it challenging for women with young children, especially, to work full-time and away from the home (for example, due to a lack of accessible and affordable childcare) (Sullivan and Lewis, 2001).

At the same time, the lack of association between men's WAH arrangements, their unpaid work time (domestic work and childcare) and their multi-tasking suggests there is a gendered element to this. First because men who WAH appear more able to maintain boundaries between employment and other activities than women (e.g. Ammons and Markham, 2004); and, second, men may WAH for different reasons than women do. For example, as Bailey and Kurland (2002) found in their study, men may do so to escape office distractions rather than to manage their employment and non-employment activities.

Overall, these findings point to a clear and gendered association between WAH amount of time (in relation to paid and unpaid work), multi-tasking and scheduling of paid work. The gendered impact of WAH is particularly strong among those who WAH regularly, which itself is gendered (Felstead et al., 2001). For both men and women, WAH for any period did not enable them to gain better work-life balance in the sense of increasing the amount of time they were able to dedicate to recreational labour (Ransome, 2007). However, for women in particular, it is likely that WAH is used to support the juggling of work and family, given the evidence that employment time is exchanged for unpaid work time and vice versa. While at the micro-level WAH may grant individual women some control over how they juggle paid and unpaid work, at a macro-level WAH reinforces gendered divisions of labour inside and outside the home.

\section{References}


ABS. (2009) Locations of Work, Nov 2008. Cat no 6275.0. Canberra: Australian Bureau of Statistics.

Ammons SK and Markham WT. (2004) Working at home: experiences of skilled white collar workers. Sociological Spectrum: Mid-South Sociological Association 24: 191 - 238.

Bailey DE and Kurland NB. (2002) A review of telework research: findings, new directions, and lessons for the study of modern work. Journal of Organizational Behavior 23: 383400.

Baines S and Gelder U. (2003) What is family friendly about the workplace in the home? The case of self-employed parents and their children. New Technology, Work and Employment 18: 223-234.

Baruch Y. (2000) Teleworking: benefits and pitfalls as perceived by professionals and managers. New Technology, Work and Employment 15: 34-49.

Berke DL. (2003) Coming Home Again: The Challenges and Rewards of Home-Based SelfEmployment. Journal of Family Issues 24: 513-546.

Bianchi SM and Milkie MA. (2010) Work and Family Research in the First Decade of the 21st Century. Journal of Marriage and Family 72: 705-725.

Bittman M and Wajcman J. (2000) The Rush Hour: The character of leisure time and gender equity. Social Forces 79: 165-189.

Boulin J, Lallement M, Messenger J, et al. (2006) Decent working time: new trends, new issues, Geneva: International Labour Office.

Callister P and Dixon S. (2001) New Zealanders' Working Time and Home Work Patterns: Evidence from the Time Use Survey. Occasional Papers 2001/5. New Zealand: Department of Labour.

Callister P and Singley SG. (2004) A double burden or the best of both worlds? A research note on simultaneous paid work and childcare in New Zealand. Working paper. New Zealand: Callister \& Associates.

Demerouti E, Derks D, Ten Brummelhuis L, et al. (2014) New ways of working: impact on working conditions, work-family balance, and well-being. In: Korunka $\mathrm{C}$ and Hoonakker P (eds) The impact of ICT on quality working life. Dordrecht: Springer Science.

Felstead A and Jewson N. (2000) In work, at home: towards an understanding of homeworking, London: Routledge.

Felstead A, Jewson N, Phizacklea A, et al. (2001) Working at Home: Statistical Evidence for Seven Key Hypotheses. Work, Employment \& Society 15: 215-231.

Felstead A, Jewson N, Phizacklea A, et al. (2002) The option to work at home: another privilege for the favoured few? New Technology, Work and Employment 17: 204-223. 
Gambles R, Lewis S and Rapoport R. (2006) The myth of work-life: the challenge of our time for men, women and societies, Chichester: John Wiley.

Golden L. (2008) Limited access: disparities in flexible work schedules and work-at-home. Journal of Family and Economic Issues 29: 86-109.

Golden TD and Veiga JF. (2005) The impact of extent of telecommuting on job satisfaction: resolving inconsistent findings. Journal of Management 31: 301-318.

Haddon L and Brynin M. (2005) The character of telework and the characteristics of teleworkers. New Technology, Work and Employment 20: 34-46.

Halford S. (2006) Collapsing the Boundaries? Fatherhood, Organization and Home-Working. Gender, Work \& Organization 13: 383-402.

Hilbrecht M, Shaw SM, Johnson LC, et al. (2008) 'I'm home for the kids': Contradictory implications for work-life balance of teleworking mothers. Gender, Work \& Organization 15: 454-476.

Hill EJ, Ferris M and Martinson V. (2003) Does it matter where you work? A comparison of how three work venues (traditional office, virtual office, and home office) influence aspects of work and personal/family life. Journal of Vocational Behavior 63: 220-241.

Kelly CGE, Kelley SMC, Evans MDR, et al. (2008) Attitudes toward homebased employment for mothers of young children: Australian evidence. International Journal of Social Welfare 19: 33-44.

Kurland NB and Bailey DE. (1999) Telework: the advantages and challenges of working here, there, anywhere, and anytime. Organizational Dynamics: 53-67.

Mann S and Holdsworth L. (2003) The pyschological impact of teleworking: stress, emotions and health. New Technology, Work and Employment 18: 196-211.

Maruyama T, Hopkinson PG and James PW. (2009) A multivariate analysis of work-life balance outcomes from a large-scale telework programme. New Technology, Work and Employment 24: 76-88.

Mattingly M and Bianchi S. (2003) Gender differences in the quantity and quality of free time: The U.S. experience. Social Forces 81: 999-1030.

Mattingly M and Sayer L. (2006) Under pressure: Gender differences in the relationship between free time and feeling rushed. Journal of Marriage and the Family 68: 205-221.

Michelson W and Linden KW. (1997) Home and telework in Sweden. Gender and Teleworking Conference. National Resource Center for Women, Stockholm, Sweden.

Morganson VJ, Major DA, Oborn KL, et al. (2010) Comparing telework locations and traditional work arrangements: differences in work-life balance support, job satisfaction and inclusion. Journal of Managerial Psychology 25: 578-595. 
Nätti J, Tammelin M, Anttila T, et al. (2011) Work at home and time use in Finland. New Technology, Work and Employment 26: 68-77.

Offer S and Schneider B. (2010) Multitasking among working families: a strategy for dealing with the time squeeze. In: Christensen K and Schneider B (eds) Workplace flexibility: realigning 20th-century jobs for a 21st-century workforce. Ithaca: Cornell University Press, 43-56.

Peters P and Van der Lippe T. (2007) The Time-Pressure Reducing Potential of Telehomeworking: the Dutch Case. International Journal of Human Resource Management 18: 430-447.

Pocock B, Skinner N and Williams P. (2012) Time Bomb: Work, rest and play in Australia today, Sydney: New South.

Ransome P. (2007) Conceptualizing boundaries between 'life' and 'work'. The International Journal of Human Resource Management 18: 374-386.

Redman T, Snape E and Ashurst C. (2009) Location, location, location: does place of work really matter? British Journal of Management 20: s171-s181.

Rubinstein JS, Meyer DS and Evans JE. (2001) Executive control of cognitive processes in task switching. Journal of Experimental Psychology 27: 763-797.

Sayer L. (2007) More work for mothers? Trends and gender differences in multitasking. In: Van der Lippe $\mathrm{T}$ and Peters $\mathrm{P}$ (eds) Competing claims in work and family life. Cheltenham: Edward Elgar, 41-55.

Schieman S and Young M. (forthcoming) Who Engages in Work-Family Multitasking? A Study of Canadian and American Workers. Social Indicators Research.

Silver H. (1993) Homework and domestic work. Sociological Forum 8: 181-204.

Sonnentag S. (2001) Work, recovery activities, and individual well-being: a diary study. Journal of Occupational Health Psychology 6: 196-210.

Sullivan C. (2003) What's in a name? Definitions and conceptualisations of teleworking and homeworking. New Technology, Work and Employment 18: 158-165.

Sullivan C and Lewis S. (2001) Home-based telework, gender and the synchronization of work and family: perspectives of teleworkers and their co-residents. Gender, Work \& Organization 8: 123-145.

Sullivan C and Smithson J. (2007) Perspectives of Homeworkers and Their Partners on Working Flexibility and Gender Equity. International Journal of Human Resource Management 18: 448-461.

Sullivan O. (1997) Time Waits For No (Wo)Man: An Investigation Of The Gendered Experience Of Domestic Time. Sociology 31: 221-239. 
Sullivan O and Gershuny J. (2013) Domestic outsourcing and multitasking: How much do they really contribute? Social Science Research 42: 1311-1324.

ten Brummelhuis L and Van Der Lippe T. (2010) Effective Work-Life Balance Support for Various Household Structures'. Human Resource Management 49: 173-193.

van den Broek D and Keating E. (2011) Rights to a process for the masses or select privileges for the few? Telework policy and labour market inequality in Australia. Policy Studies 32: 21-33. 
Original article available at: https://doi.org/10.1177/0950017014568140

Table 1: Descriptive analysis: amount of time in activities, multi-tasking and fragmentation by WAH arrangement and gender

\begin{tabular}{|c|c|c|c|c|c|c|c|c|}
\hline & \multicolumn{4}{|c|}{ Men } & \multicolumn{4}{|c|}{ Women } \\
\hline & $\begin{array}{l}\text { No WAH on } \\
\text { diary day (dd) }\end{array}$ & $\begin{array}{l}\text { WAH on dd } \\
\text { but not usually } \\
\text { (rarely) }\end{array}$ & $\begin{array}{l}\text { WAH on dd } \\
\text { usually }<50 \% \\
\text { (occasionally) }\end{array}$ & $\begin{array}{c}\text { WAH on dd } \\
\text { usually }=>50 \% \\
\text { (regularly) }\end{array}$ & $\begin{array}{l}\text { No WAH on } \\
\text { diary day (dd) }\end{array}$ & $\begin{array}{l}\text { WAH on dd } \\
\text { but not usually } \\
\text { (rarely) }\end{array}$ & $\begin{array}{l}\text { WAH on dd } \\
\text { usually }<50 \% \\
\text { (occasionally) }\end{array}$ & $\begin{array}{c}\text { WAH on dd } \\
\text { usually }=>50 \% \\
\text { (regularly) }\end{array}$ \\
\hline \multicolumn{9}{|c|}{ A. Amount of time in activities (mins per day) } \\
\hline \multicolumn{9}{|c|}{ Employment } \\
\hline Employment excluding travel & 481 & 442 & 411 & 446 & 409 & 345 & 339 & 238 \\
\hline Employment-related travel & 57 & 48 & 37 & 13 & 49 & 34 & 34 & 11 \\
\hline \multicolumn{9}{|l|}{ Unpaid work } \\
\hline Domestic work & 49 & 72 & 76 & 72 & 93 & 118 & 139 & 191 \\
\hline Childcare & 21 & 25 & 41 & 34 & 30 & 30 & 45 & 120 \\
\hline \multicolumn{9}{|l|}{ Recreational labour } \\
\hline Personal care & 116 & 107 & 120 & 110 & 132 & 130 & 127 & 123 \\
\hline Sleep & 477 & 491 & 489 & 470 & 484 & 500 & 488 & 494 \\
\hline Leisure & 204 & 216 & 217 & 236 & 187 & 212 & 201 & 194 \\
\hline \multicolumn{9}{|l|}{ B. Multi-tasking (mins per day) } \\
\hline $\begin{array}{l}\text { Employment (excluding travel) } \\
\text { and simultaneous childcare }\end{array}$ & 0.3 & 0.8 & 6.0 & 6.3 & 1.4 & 5.1 & 4.9 & 24.4 \\
\hline \multicolumn{9}{|c|}{ C. Fragmentation of time (mean count) } \\
\hline $\begin{array}{l}\text { Episodes of employment } \\
\text { (excluding travel) }\end{array}$ & 2.7 & 3.5 & 4.2 & 5.4 & 2.7 & 3.4 & 4.0 & 3.8 \\
\hline
\end{tabular}

Note: weighted data 
Original article available at: https://doi.org/10.1177/0950017014568140

Table 2: Multivariate analysis summary: main effects of independent variables in each model by WAH arrangement and gender

\begin{tabular}{|c|c|c|c|c|c|c|c|c|}
\hline & \multicolumn{4}{|c|}{ Men } & \multicolumn{4}{|c|}{ Women } \\
\hline & $\begin{array}{l}\text { Constant: No } \\
\text { WAH on diary } \\
\text { day (dd) }\end{array}$ & $\begin{array}{l}\text { WAH on dd } \\
\text { but not usually } \\
\text { (rarely) }\end{array}$ & $\begin{array}{l}\text { WAH on dd } \\
\text { usually }<50 \% \\
\text { (occasionally) }\end{array}$ & $\begin{array}{c}\text { WAH on dd } \\
\text { usually }=>50 \% \\
\text { (regularly) }\end{array}$ & $\begin{array}{l}\text { Constant: No } \\
\text { WAH on diary } \\
\text { day (dd) }\end{array}$ & $\begin{array}{l}\text { WAH on dd } \\
\text { but not usually } \\
\text { (rarely) }\end{array}$ & $\begin{array}{l}\text { WAH on dd } \\
\text { usually }<50 \% \\
\text { (occasionally) }\end{array}$ & $\begin{array}{c}\text { WAH on dd } \\
\text { usually }=>50 \% \\
\text { (regularly) }\end{array}$ \\
\hline \multicolumn{9}{|c|}{ A. Amount of time in activities (mins per day): OLS coefficients } \\
\hline \multicolumn{9}{|c|}{ Employment } \\
\hline Employment excluding travel & $526.3 * * *$ & $-30.0 * *$ & $-41.5 * * *$ & -22.1 & $396.0 * * *$ & $-57.9 * * *$ & $-65.8 * * *$ & $-152.8 * * *$ \\
\hline Employment-related travel & $59.2 * * *$ & $-8.3 * *$ & $-20.9 * * *$ & -48.1 & $42.3 * * *$ & $-13.8 * * *$ & $-14.0 * * *$ & $-33.3 * * *$ \\
\hline \multicolumn{9}{|l|}{ Unpaid work } \\
\hline Domestic work & $47.9 * * *$ & $20.9 * * *$ & $20.5^{* * *}$ & 18.6 & $129.0 * * *$ & $25.2 * * *$ & $42.3 * * *$ & $77.6^{* * *}$ \\
\hline Childcare & $51.6^{* * *}$ & 4.5 & $11.4 * * *$ & 8.2 & $101.0 * * *$ & 4.6 & $11.8 *$ & $60.1 * * *$ \\
\hline \multicolumn{9}{|l|}{ Recreational labour } \\
\hline Personal care & $108.0 * * *$ & $-10.5^{*}$ & -0.5 & -11.9 & $114.3^{* * *}$ & -3.8 & -9.4 & -7.5 \\
\hline Sleep & $469.4 * * *$ & $14.5^{*}$ & $13.9^{*}$ & -2.2 & $471.7 * * *$ & $12.3^{*}$ & 10 & 17.2 \\
\hline Leisure & $150.6 * * *$ & 5.9 & 5.7 & 35.3 & $138.4 * * *$ & $18.0^{*}$ & 8.5 & 18.6 \\
\hline \multicolumn{9}{|c|}{ B. Multi-tasking (mins per day): OLS coefficients } \\
\hline Employment and childcare & $1.8 * * *$ & 0.4 & $5.5 * * *$ & 6.2 & $7.2 * * *$ & 3.6 & 2.9 & $20.9 * * *$ \\
\hline \multicolumn{9}{|c|}{ C. Fragmentation of time (mean count): Poisson marginal effects } \\
\hline Episodes of employment & $3.1 * * *$ & $1.0 * * *$ & $2.0 * * *$ & $3.2 * * *$ & $2.8^{* * *}$ & $0.8 * * *$ & $1.0 * * *$ & $1.8 * * *$ \\
\hline
\end{tabular}


Figure 1: Scheduling of employment (mean minutes per hour)

... No WAH on diary day

- WAH rarely

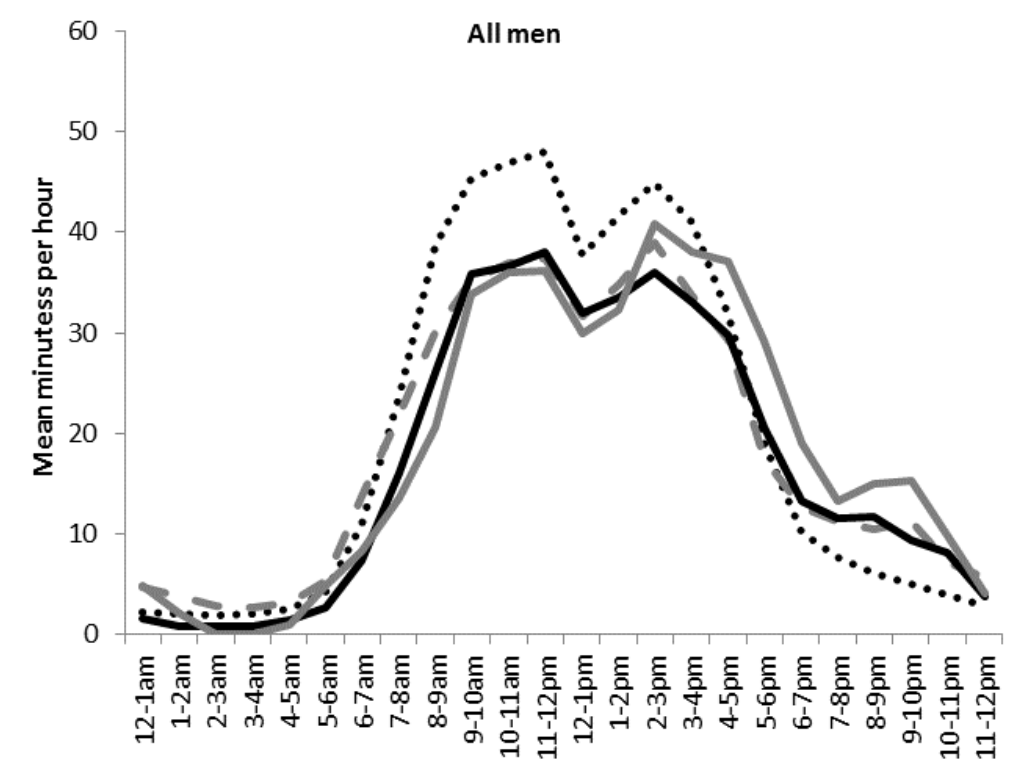

WAH occasionally

WAH reguarly

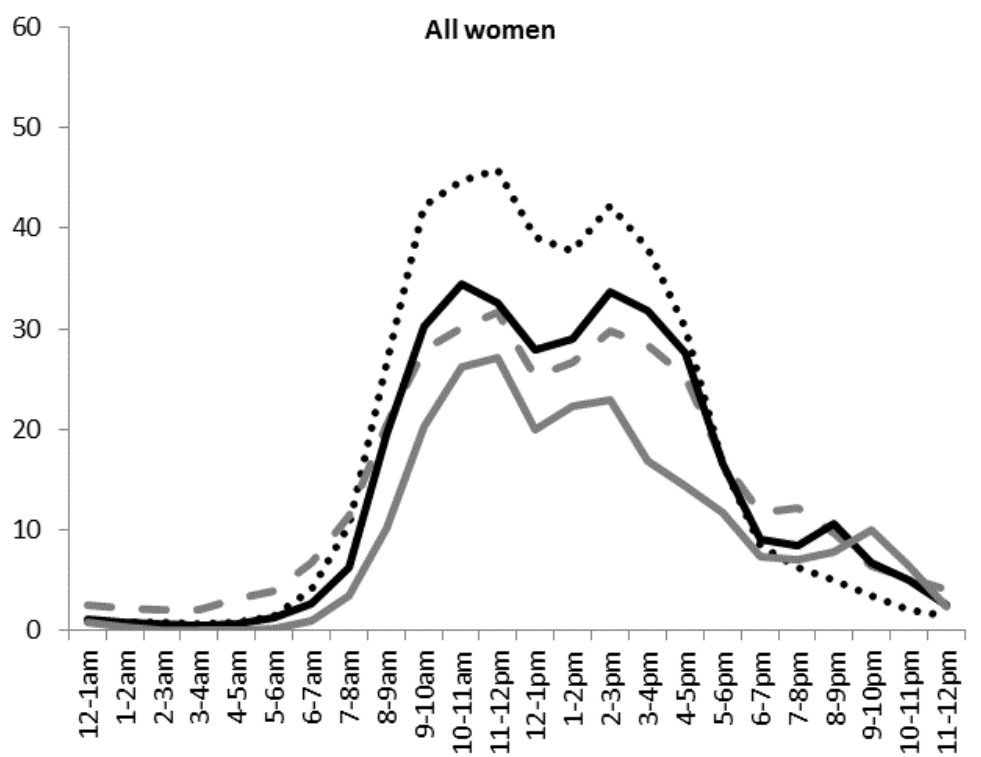

